\title{
Isolation, identification, and detection of ACC deaminase gene-encoding rhizobacteria from rhizosphere of stressed pineapple
}

\author{
Dori Kusuma Jaya ${ }^{1}$, Giyanto $^{2,}$, Novik Nurhidayat $^{3}$, and Sarjiya Antonius ${ }^{3}$ \\ ${ }^{1}$ Graduate School of Soil and Environmental Biotechnology, Department of Soil Science and Land Resources, Faculty of Agriculture, Bogor \\ Agricultural University, Jalan Ulin, Babakan, Kampus IPB Dramaga, Bogor 16680, Indonesia \\ ${ }^{2}$ Department of Plant Protection, Faculty of Agriculture, Bogor Agricultural University, Jalan Kamper, Babakan, Kampus IPB Dramaga, \\ Bogor 16680, Indonesia \\ ${ }^{3}$ Research Center for Biology, Indonesian Institute of Sciences, Jalan Raya Bogor Km 46, Cibinong, Bogor 16911, Indonesia \\ *Corresponding author: giyanto2@yahoo.com
}

SUBMITTED 22 September 2018 REVISED 19 November 2018 ACCEPTED 24 May 2019

\begin{abstract}
ACC deaminase is a microbial cytoplasmic enzyme that cleaves ACC, a precursor of ethylene, in the stressed plant. The aims of this study were to isolate, identify, and detect the presence of ACC deaminase gene-encoding rhizobacteria from the rhizospheric soil of pineapple plants that have been exposed to abiotic and biotic stress, specifically herbicide, flooding, and Phytophthora spp. stress. A total of 49 rhizobacterial isolates were obtained, seven of which were observed for their growth on DF medium containing $3 \mathrm{mM} \mathrm{L}^{-1}$ ACC. The four best-growing isolates were selected for genomic DNA extraction. They were molecularly identified as Stenotrophomonas maltophilia (3), Burkholderia territorii (2A), Pseudomonas oryzihabitans (5B), and Bacillus tropicus (1E). A set of primers, 105F-acdS 5'-TGCCAAGCGTGAAGACTGC-3' and 244R-acdS 5'-GGGTCTGGTTCGACTGGAT-3', were constructed to amplify the ACC deaminase gene (acdS). Based on melt peak curve analysis, four products appeared to show a specific single peak at $86,89,87$, and $89.5^{\circ} \mathrm{C}$, indicating a single product was produced. In addition, a Blast search showed that these four products met the ACC deaminase feature and their acdS sequences were clustered into an ancestral group compared with the bacterial strains deposited in GenBank. These results suggest that ACC deaminase gene-encoding rhizobacteria from a pineapple plantation of tropical origin may affect the acd S sequences and may contribute to the host plant's stress tolerance.
\end{abstract}

KEYWORDS ACC deaminase; acdS gene; environmental stress; ethylene; rhizobacteria

\section{Introduction}

Tropical plants are unable to escape from environmental pressures. Major stresses such as drought, heavy metals, excessive use of chemical fertilizer, and pathogenic infections adversely affect the survival, biomass production, and yield of major food crops by more than 50-70\% (Bray et al. 2000; Kaur et al. 2008; Thakur et al. 2010). In Indonesia, a wide number of abiotic and biotic stresses have overwhelmed its agricultural land. The excessive and continuous use of chemical fertilizers, pesticides, and plant pathogens have also contributed to the contamination of local soil and impacted plant health. In this study, pineapple plants originating from a plantation belonging to PT Great Giant Food in Lampung, Indonesia, which were growing well under the pressures of incidental herbicide overuse, poor irrigation, and Phytophthora spp. infections in the rhizosphere, were considered, specifically in terms of the ACC deaminase-related rhizobacteria.

One of the critical mechanisms of a plant in responding to stress is the excessive synthesis of ethylene. Ethylene is a hormone that is synthesized from 1-aminocyclo- propane-1-carboxylate (ACC), an immediate precursor, through a biochemical mechanism caused by stress stimulation (Glick 2014). ACCs are also produced by indole3-acetic acid (IAA) induction that stimulates ACC synthase activity (Kende 1993). This compound in root exudate is consumed by soil bacteria and cloven by ACC deaminase into $\alpha$-ketobutyrate and ammonia (Honma and Shimomura 1978). Therefore, rhizobacteria that produce ACC deaminase can use the product of ACC metabolism as a nitrogen source, unlike other bacteria. Ultimately, rhizobacteria play a role as a sink for ACC and maintain an internal and external plant ethylene equilibrium (Varma et al. 2004). Through this mechanism, ACC deaminaseproducing bacteria associated with the plant root are automatically capable of reducing ethylene levels and promoting plant growth by IAA (Glick et al. 1998, 2007). ACC deaminase-encoding rhizobacteria and the presence of the corresponding gene have been widely studied at the biochemical and molecular levels. ACC deaminase is a cytoplasmic enzyme encoded by the acdS gene.

The acdS gene is a structural gene whose expression is regulated differently depending on the presence of oxy- 
gen, substrate, and product accumulation. There are still less-understood regulatory mechanisms found in various genera of bacteria. The presence of this gene is very common in actinobacteria, Deinococcus-Thermus, proteobacteria and various fungi (Singh et al. 2015). Recently, in Indonesia, the study of ACC deaminase-producing bacteria has begun to intensify, but its screening and molecular study continues to be very limited. Therefore, further studies of acdS gene are essential to obtain a bioinformatic and molecular view that will result in an efficient and effective way to obtain the related bacteria.

\section{Materials and methods}

\subsection{Isolation and screening of ACC deaminase- producing rhizobacteria}

Rhizobacterial isolates were isolated from the rhizospheric soil of stressed pineapple plants in a pineapple plantation belonging to PT Great Giant Food, Lampung, Indonesia. The isolates were derived from three types of rhizosperic soil, namely those which had undergone herbicide stress, flooding stress, and Phytophthora spp. stress.

Firstly, isolation and the purification of isolates were carried out on Tryptic Soy Agar (TSA) medium. Screening for ACC-consuming strains was subsequently performed by reculturing the isolates on Dworkin-Foster (DF) minimal medium (Penrose and Glick 2003), with some modifications. The previous study's medium used DF broth, whereas in this study DF agar was used. Three culture media were used: (1) DF medium alone; (2) DF medium containing $\left(\mathrm{NH}_{4}\right)_{2} \mathrm{SO}_{4}$; and DF medium containing $3 \mathrm{mM} \mathrm{L}^{-1}$ ACC as a sole source of nitrogen. The growth of isolates was categorized into four groups: no growth (-), where no bacterial colony was observed after 24 h; fair growth $(+)$, where a bacterial colony was observed after $48 \mathrm{~h}$; good growth $(++)$, where a bacterial colony was observed after $24 \mathrm{~h}$, and a good colony was found; and best growth (+++), where a bacterial colony was observed after $24 \mathrm{~h}$, and an abundant colony was found. The capability of the bacteria to grow on the selective medium containing ACC suggests that these bacteria genetically encoded ACC deaminase.

\subsection{DNA extraction and molecular identification of ACC deaminase-producing rhizobacteria}

\subsubsection{Bacterial culture condition and DNA extraction}

A single colony of pure isolate on selective medium was inoculated into $25 \mathrm{~mL}$ of Luria-Bertani (LB) broth and incubated overnight. Subsequently, $1 \%$ of the culture was transferred into $10 \mathrm{~mL}$ of the same medium. The culture was incubated in a $100 \mathrm{rpm}$ rotary shaker at room temperature for $4 \mathrm{~h}$. For DNA extraction, a couple of $1.5 \mathrm{~mL}$ of each sample were centrifuged at $15,000 \mathrm{~g}$ for $1 \mathrm{~min}$ and the supernatant was discarded. The extraction was carried out using the Presto ${ }^{\mathrm{TM}}$ Mini gDNA Bacteria Kit (GeneAid, Taiwan), following the manufacturer's protocol. DNA samples were then stored in elution buffer $(\mathrm{pH}$ 8.5) at $-20^{\circ} \mathrm{C}$.

\subsection{2. $16 \mathrm{~S}$ rRNA gene amplification}

The ACC deaminase-producing rhizobacteria were then molecularly identified based on the 16S rRNA gene. The gene was amplified using primers 27F 5'-AGAGTTTGATCCTGGCTCAG-3' and 1492R 5'GGTTACCTTGTTACGACTT-3' (Lane 1991). PCR was performed in a $25-\mu \mathrm{L}$ reaction volume consisting of $12.5 \mu \mathrm{L} \mathrm{GoTaq}{ }^{\circledR}$ Green PCR Master Mix (2X) (Promega, United States), $0.5 \mu \mathrm{L}(0.2 \mu \mathrm{M})$ of each primer, $9.5 \mu \mathrm{L}$ nuclease-free water, and $1-2 \mu \mathrm{L}(19.4$ to $148 \mathrm{ng} / \mu \mathrm{L})$ DNA template. The PCR protocol was set at $94^{\circ} \mathrm{C}$ for 3 min, followed by 40 cycles of $95^{\circ} \mathrm{C}$ for $30 \mathrm{~s}, 58^{\circ} \mathrm{C}$ for 30 $\mathrm{s}, 72^{\circ} \mathrm{C}$ for $1.5 \mathrm{~min}$, and completed with $72^{\circ} \mathrm{C}$ for $5 \mathrm{~min}$, following the Kit protocol. PCR was carried out using a Takara thermal cycler. Following PCR, electrophoresis of the products was performed at $100 \mathrm{~V}$ for $45 \mathrm{~min}$. The products were further visualized on $0.8 \%$ agarose gel. The products were then sequenced using an ABI-Prism $3730 \mathrm{xl}$ DNA Sequencer (1st BASE, Malaysia) using the 27F primer.

\subsection{Primer design for acdS gene detection}

Initially, a bioinformatic study of the acdS gene was conducted to obtain identified sequences deposited in the GenBank sequence database (http://www.ncbi.nlm.nih.gov). Five strains of Pseudomonas spp., P. putida UW4 (AY823987), P. fluorescens KACC 10070 (JQ646055), P. entomophila PS-PJH (FJ882923), P. oryzihabitans LP11 (JF741959), and Pseudomonas sp. ACP (M73488) were used for the alignment process using the MUSCLE application, which is integrated in the MEGA 7.0 program. A couple of primers were then constructed based on the conserved and unique regions of the acdS sequence. The characters of the primer were then evaluated using the NetPrimer program (www.primerbiosoft.com/netprimer.html) and the primer homology was analyzed using a BlastN search.

\subsection{Amplification of acdS gene using real-time PCR- based method}

A couple of primers, namely 105F-acdS 5'TGCCAAGCGTGAAGACTGC-3' and 244R-acdS 5'-GGGTCTGGTTCGACTGGAT-3', were designed to amplify a 140 bp partial acdS sequence using real-time PCR. PCR was performed in a $20-\mu \mathrm{L}$ reaction volume consisting of $10 \mu \mathrm{L}$ KAPA SYBR ${ }^{\circledR}$ Fast qPCR Master Mix (2X) (Promega, United States), $1 \mu \mathrm{L}(0.2 \mu \mathrm{M})$ of each primer, 6-7 $\mu \mathrm{L}$ nuclease-free water, and 1-2 $\mu \mathrm{L}$ (19.4 to $148 \mathrm{ng} / \mu \mathrm{L}$ ) DNA template. A no template control (NTC) was used as a negative control reaction. The PCR protocol was set at $95^{\circ} \mathrm{C}$ for $3 \mathrm{~min}$ and then followed by 40 cycles of $95^{\circ} \mathrm{C}$ for $30 \mathrm{~s}$ and $58^{\circ} \mathrm{C}$ for $30 \mathrm{~s}$, following the Kit protocol. After the PCR process, the melt peak chart was analyzed for whether the amplicon generated a specific single peak in the chart and described the meaning of the generated peak. The PCR was conducted using a real-time PCR thermal cycler (Bio-Rad). 


\subsection{Sequencing and bioinformatic study of amplified acdS gene}

The amplified products were sequenced using primer 244R-acdS 5'-GGGTCTGGTTCGACTGGAT-3' in the ABI-Prism $3730 \mathrm{xl}$ DNA Sequencer (1st BASE, Malaysia) and BlastN and BlastX searches in the NCBI database were performed. Furthermore, the acdS sequences and Blast search results were analyzed by observing the percentage of similarity sequence, GC content, homology, query cover, aligned sequence, and gene feature.

\subsection{Phylogenetic tree construction of acd $S$ gene}

A phylogenetic tree was constructed using the MEGA 7.0 program and tested with 1000 bootstrap replications. Sequences were aligned with the MUSCLE program and analyzed using the maximum-likelihood method based on Tamura-3-parameters.

\section{Results}

\subsection{ACC deaminase-producing rhizobacterial isolates}

Out of 49 bacterial isolates grown on Tryptic Soy Agar, only seven were observed on selective medium consuming ACC as a sole source of nitrogen. The DNA samples of four selected isolates (marked 3, 2A, 5B, and 1E) were used as templates for the PCR reaction. Table 1 demonstrates the growth performance of the isolates on the selective medium. It can be seen that four bacterial colonies did not have ability to grow on DF medium alone but grew very well on DF medium containing ammonium sulfate. The four isolates grew on DF medium containing ACC, which indicates that they are ACC consumers.

\subsection{Molecular identification of ACC deaminase- producing rhizobacteria}

Four bacterial isolates showed a single band at around $1500 \mathrm{bp}$, indicating that the 16S rRNA gene was successfully amplified (Figure 1). They were identified as Stenotrophomonas maltophilia (3), Burkholderia territorii (2A), Pseudomonas oryzihabitans (5B), and Bacillus tropicus (1E), following the BlastN search (Table 2). An investigation of several previous studies revealed that the four genera of bacteria considerably belong to a group of ACC consumers.

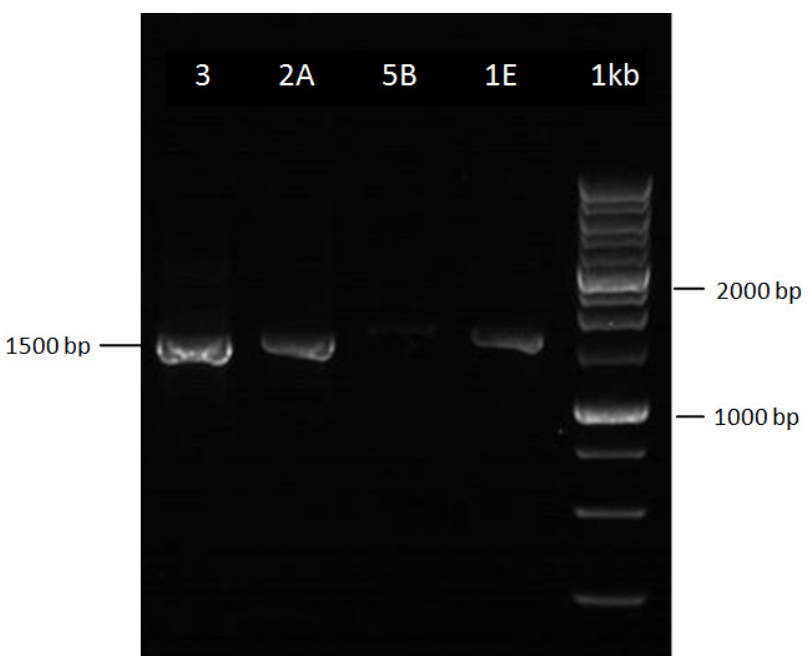

FIGURE 1 Visualization of $16 \mathrm{~S}$ rRNA gene of ACC deaminaseproducing rhizobacteria on $0.8 \%$ agarose gel. $3,2 \mathrm{~A}, 5 \mathrm{~B}, 1 \mathrm{E}=\mathrm{DNA}$ samples. $1 \mathrm{~kb}=$ DNA marker.

\subsection{Primer set for acdS gene detection}

The primer sequence derived from the alignment process of the complete acdS coding sequence of Pseudomonas spp. deposited in the NCBI database. Figure 2 shows the sequence alignment among the acdS sequences to generate a couple of primers oriented from 5' to 3'.

Further analysis indicated the characters of the designed primer sequence with a nucleotide position and product length based on P. putida UW4 as a reference (Table 3). In this result, we found that there were still inappropriate characters, such as a GC clamp and primer dimer, which are acceptable if the reaction is well-optimized.

\subsection{Detection of acdS gene using real-time PCR-based method}

Initially, a preliminary test was performed to obtain the best annealing temperature of the primers in sample $1 \mathrm{E}$, which was at $58^{\circ} \mathrm{C}$ (data not shown). Figure 3 illustrates the melt peak chart of the partial acdS sequence, which is denoted by the highest melt temperature. Putative amplified acdS sequences are indicated by a specific single peak in sample 3, 2A, 5B, and $1 \mathrm{E}$, which melted at 86, 89,87 , and $89.5^{\circ} \mathrm{C}$, respectively. Meanwhile, the lower melt temperatures, the lower peaks of which were at 78.5, 81,81 , and $80.5^{\circ} \mathrm{C}$, indicate an intermediate state between

TABLE 1 Growth performance of four rhizobacterial isolates on selective medium.

\begin{tabular}{lllll}
\hline \multirow{2}{*}{ Isolate } & \multicolumn{3}{c}{ Growth } & Source \\
\cline { 2 - 4 } & $\mathrm{DF}$ & $\mathrm{DF}+\left(\mathrm{NH}_{4}\right) \mathrm{SO}_{4}$ & $\mathrm{DF}+\mathrm{ACC}$ & \\
\hline 3 & - & +++ & + & Laboratorium collection \\
$2 \mathrm{~A}$ & - & +++ & +++ & Rhizosphere of flooding stress \\
$5 \mathrm{~B}$ & - & +++ & +++ & Rhizosphere of herbicide stress \\
$1 \mathrm{E}$ & - & +++ & + & Rhizosphere of Phytophthora spp. stress \\
\hline
\end{tabular}

$(-)=$ no growth; $(+)=$ fair growth; $(++)=$ good growth; $(+++)=$ best growth. 
TABLE 2 BlastN search of 16S rRNA gene of ACC deaminase-producing rhizobacteria.

\begin{tabular}{llccccc}
\hline Isolate & Strain & $\begin{array}{c}\text { Sequence length } \\
(\mathrm{bp})\end{array}$ & Query cover (\%) & E-value & $\begin{array}{l}\text { Identity (\%) } \\
\text { Accession } \\
\text { number }\end{array}$ \\
\hline 3 & Stenotrophomonas maltophilia IAM 12423 & 1538 & 100 & 0.0 & 99 & NR_041577 \\
& Stenotrophomonas pavanii LMG 25348 & 1497 & 100 & 0.0 & 99 & NR_118008 \\
& Stenotrophomonas tumulicola T5916-2-1b & 1472 & 100 & 0.0 & 99 & NR_148818 \\
\multirow{2}{*}{ 2A } & Burkholderia territorii LMG 28158 & 1443 & 99 & 0.0 & 99 & NR_136496 \\
& Burkholderia cepacia NBRC 14074 & 1458 & 99 & 0.0 & 99 & NR_113645 \\
& Burkholderia contaminans J2956 & 1485 & 99 & 0.0 & 99 & NR_104978 \\
5 5B & Pseudomonas oryzihabitans IAM 1568 & 1466 & 99 & 0.0 & 99 & NR_115005 \\
& Pseudomonas psychrotolerans C36 & 1459 & 99 & 0.0 & 99 & NR_042191 \\
& Pseudomonas oleovorans IAM 1508 & 1526 & 99 & 0.0 & 98 & NR_043423 \\
1E & Bacillus tropicus MCCC 1A01406 & 1509 & 92 & 0.0 & 84 & NR_157736 \\
& Bacillus proteolyticus MCCC 1A00365 & 1509 & 92 & 0.0 & 84 & NR_157735 \\
& Bacillus anthracis ATCC 14578 & 1306 & 90 & 0.0 & 84 & NR_041248 \\
\hline
\end{tabular}

dsDNA and ssDNA, primer dimer formation, and/or nonspecific amplification.

\subsection{Alignment and bioinformatic analysis of amplified acdS gene \\ 3.5.1. Alignment of partial acdS sequence and amino acids of ACC deaminase}

Figure 4 shows the alignment of the partial acdS sequence and shows the relatively different GC distribution between them. The identical percentages of the four sequences of Stenotrophomonas maltophilia, Burkholderia territorii, Pseudomonas oryzihabitanas, Bacillus tropicus to that of $P$. putida UW4 were $70.71 \%, 78.57 \%, 67.14 \%$, and $78.57 \%$, respectively, while the GC contents were $55.71 \%$, $60 \%, 48.57 \%$, and $58.57 \%$, respectively. The higher GC content and distribution may contribute to the shape of the peak in the melt peak chart, where the higher the GC content, the higher the melt temperature would be. Meanwhile, sequence similarity may contribute to the construction of the phylogenetic tree. In primer $105 \mathrm{~F}$-acdS of sample $5 \mathrm{~B}$, there was one base that did not match at position 120 , which is estimated as a point mutation. The amino acid sequence in Figure 5 shows the closest amino acid sequence similarity between species and those deposited in the GenBank database.

\subsubsection{BlastN and BlastX search of $\mathrm{acd} S$ sequence}

A BlastN search revealed that the amplified acdS sequences corresponded to those of various strains deposited in the GenBank database by up to 89-96\% identity (Table 4). It also confirmed that the complete coding sequence of the acdS gene was in the range of 1016-1017 bp, corresponding to that of $P$. putida UW4. The acdS gene found in this study was found to be distributed in diverse strains of many bacteria deposited in the GenBank database.

A BlastX search was carried out to find the corresponding amino acid sequences of ACC deaminase between those of this study and those in the GenBank database (Table 5). The BlastX search revealed that the identity of amino acid ranged from $63 \%$ to $100 \%$. This means that the lower identity level indicates a partial amino acid sequence.

\subsection{Phylogenetic analysis of acdS gene}

Figure 6 shows the construction of a phylogenetic tree of various bacteria based on the partial acdS sequence. The amplified acdS sequence showed a relatively high proximity between Burkholderia territorii and Bacillus tropicus but was relatively different from Stenotrophomonas maltophilia and Pseudomonas oryzihabitans. The acdS sequence of those two bacteria had a close resemblance to that of Ralstonia mannitolylitica SN82F48 (CP010800). Although it belongs to Proteobacteria group, the sequence of Stenotrophomonas maltophilia was still relatively apart from that of Pseudomonas oryzihabitans. Compared with many strains deposited in the GenBank database (as of November 2018), the four strains were clustered into an ancestral group (Group II).

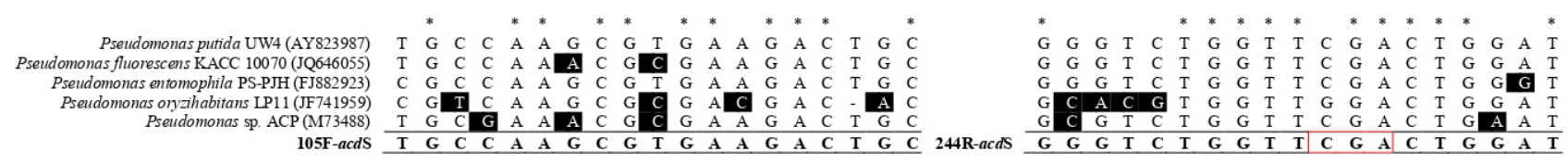

FIGURE 2 Alignment of acdS sequence to design primers 105F-acdS and 244R-acdS ( 5 ' to 3'). Accession numbers are given in parentheses. Black boxes indicate mismatched nucleotides among sequences. Red rectangle represents a complementary specific codon for the acdS gene. 
TABLE 3 Characters of oligonucleotide primer based on NetPrimer analysis.

\begin{tabular}{|c|c|c|}
\hline Characters & $\begin{array}{l}\text { Primer } \\
\text { 105F-acdS }\end{array}$ & $\begin{array}{l}\text { Primer } \\
\text { 244R-acdS }\end{array}$ \\
\hline Sequence length & $19 \mathrm{bp}$ & $19 \mathrm{bp}$ \\
\hline${ }^{*}$ Nucleotide position & $105-123$ & $226-244$ \\
\hline Product size & & $140 \mathrm{bp}$ \\
\hline Molecular weight & 5837.88 & 5890.89 \\
\hline $\begin{array}{l}\text { Melting temperature } \\
(\mathrm{Tm})\end{array}$ & $60.26^{\circ} \mathrm{C}$ & $56.51^{\circ} \mathrm{C}$ \\
\hline GC\% & 57.89 & 57.89 \\
\hline GC clamp & 2 & 2 \\
\hline$\Delta \mathrm{G}$ & $-33.93 \mathrm{kcal} / \mathrm{mol}$ & $-32.24 \mathrm{kcal} / \mathrm{mol}$ \\
\hline 3' end stability & - $8.03 \mathrm{kcal} / \mathrm{mol}$ & - $8.07 \mathrm{kcal} / \mathrm{mol}$ \\
\hline $5^{\prime}$ end $(\Delta G)$ & - $10.12 \mathrm{kcal} / \mathrm{mol}$ & - $9.06 \mathrm{kcal} / \mathrm{mol}$ \\
\hline Self dimer $(\Delta G)$ & - & - $6.76 \mathrm{kcal} / \mathrm{mol}$ \\
\hline Hairpin $(\Delta \mathrm{G})$ & - & - \\
\hline Repeats (\# of pairs) & - & - \\
\hline Run (\# of bases) & - & 3 \\
\hline Cross dimer $(\Delta \mathrm{G})$ & & $-6,02 \mathrm{kcal} / \mathrm{mol}$ \\
\hline
\end{tabular}

Reaction condition: Oligo concentration: $250 \mathrm{pM}$; free $\mathrm{Mg}^{2+}$ concentration: $1.5 \mathrm{mM}$.

${ }^{*}$ Nucleotide position of acdS sequence of P. putida UW4.

\section{Discussion}

ACC deaminase-producing rhizobacteria are a group of bacteria that have been studied intensively throughout the world, because they have been considered to lower overproduced ethylene in stressed plants. They were found to be relatively common in rhizosphere associated with environmental stress and with a broad geographical range around the globe (Timmusk et al. 2011; Glick 2014). The distribution of this type of bacteria varies depending on its geographical origin and plant host or even environmental stress. In this study, a number of rhizobacterial isolates were successfully obtained, $14.28 \%$ of which were positive for ACC consumption, suggesting that only certain bacteria were able to grow. These growing bacteria are considered to have ACC deaminase. Bal et al. (2013) reported that $10.61 \%$ of the total isolates from the soil of tropical rice plants in India are ACC-consuming strains. However, the four selected isolates did not belong to nitrogen-fixing bacteria, because no bacterial colony was observed on the DF medium alone (Table 1). Ma et al. (2003) reported that 38\% of rhizobial strains from many studies and different legume hosts were able to express ACC deaminase, whereas Duan et al. (2009) reported that $12 \%$ of those that experienced harsh winters and a lack of diverse vegetation expressed ACC deaminase. The discrepancy of these reports on the frequency of ACC deaminase-producing rhizobacteria is affected by their geographical conditions and plant hosts, which in adverse conditions lead to a lower diversity of rhizobacteria. This investigation found that tropical conditions and biotic and

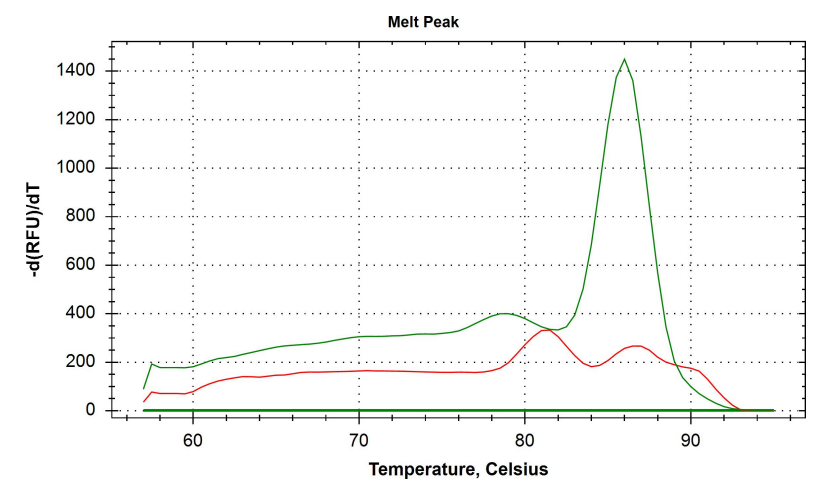

(a)

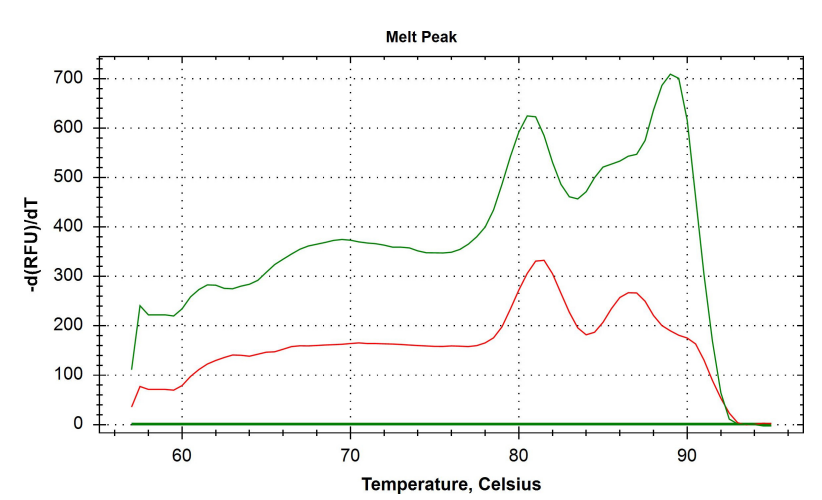

(b)

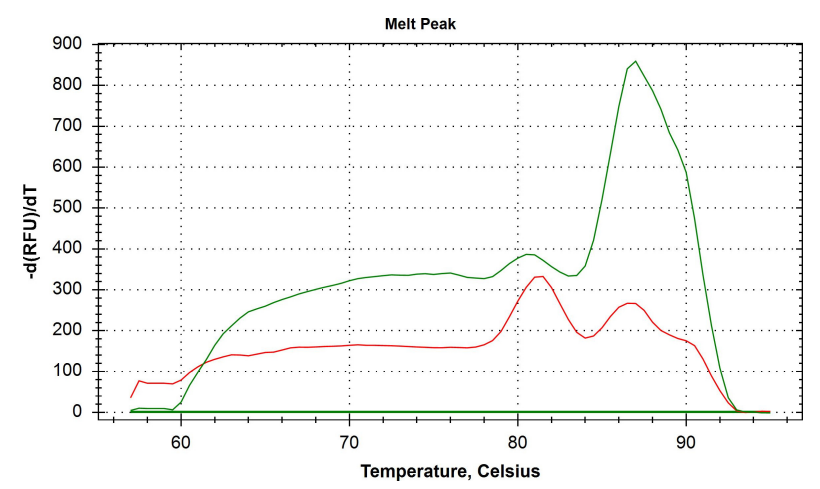

(c)

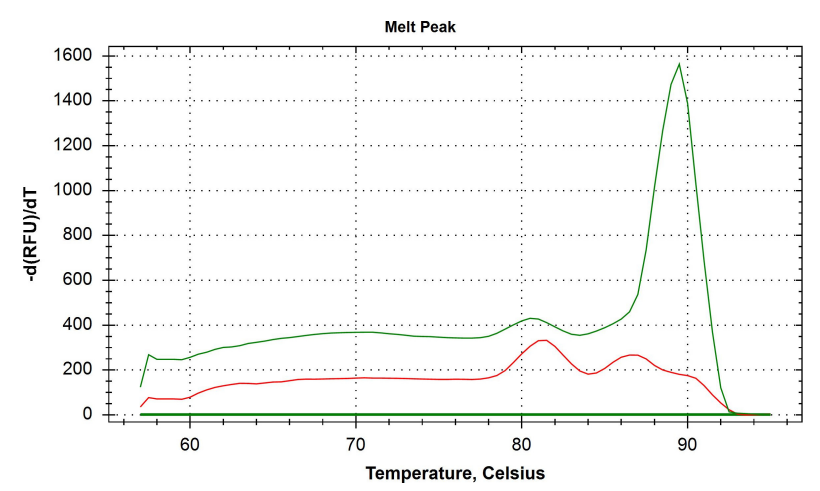

(d)

FIGURE 3 Melt peak chart of amplified partial acdS sequences of four DNA samples with relatively similar melting temperatures to each other. (a) $3: 86^{\circ} \mathrm{C}$; (b) $2 \mathrm{~A}: 89^{\circ} \mathrm{C}$; (c) $5 \mathrm{~B}: 87^{\circ} \mathrm{C}$; (d) $1 \mathrm{E}: 89.5^{\circ} \mathrm{C}$. Red line represents no template control (NTC). Green line represents sample. 
TABLE 4 BlastN search of amplified acdS sequence in the NCBI sequence database.

\begin{tabular}{lllcccc}
\hline Isolate & Strain & Feature & Sequence length (bp) & Query cover (\%) & $\begin{array}{c}\text { Identity (\%) } \\
\text { Accession } \\
\text { number }\end{array}$ \\
\hline 3 & Ralstonia solanacearum CMR15 & acdS gene & 1016 & 58 & 91 & FP885896 \\
& Pseudomonas sp. PNSL & acdS gene & 1017 & 60 & 90 & DQ830987 \\
& Burkholderia phenazinium LMG2247 & acdS gene & 801 & 51 & 90 & DQ125252 \\
\multirow{2}{*}{ 2A } & Ralstonia mannitolilytica SN82F48 & acdS gene & 1016 & 86 & 93 & CP010800 \\
& Methylibium petroleiphilum PM1 & acdS gene & 1016 & 86 & 89 & CP000555 \\
& Variovorax sp. HW608 & acdS gene & 1016 & 75 & 91 & LT607803 \\
5 5B & Pseudomonas putida NX-1 & acdS gene & 1016 & 52 & 90 & CP030750 \\
& Pseudomonas putida PC2 & acdS gene & 1016 & 53 & 89 & CP011789 \\
1E & Ralstonia mannitolilytica SN82F48 & acdS gene & 1016 & 83 & 96 & CP010800 \\
& Pseudomonas fluorescens L111 & acdS gene & 1016 & 76 & 91 & CP015638 \\
& Acidovorax sp. RAC01 & acdS gene & 1016 & 67 & 95 & CP016447 \\
\hline
\end{tabular}

3 = Stenotrophomonas maltophilia; 2A = Burkholderia territorii; 5B = Pseudomonas oryzihabitans; $1 \mathrm{E}=$ Bacillus tropicus.

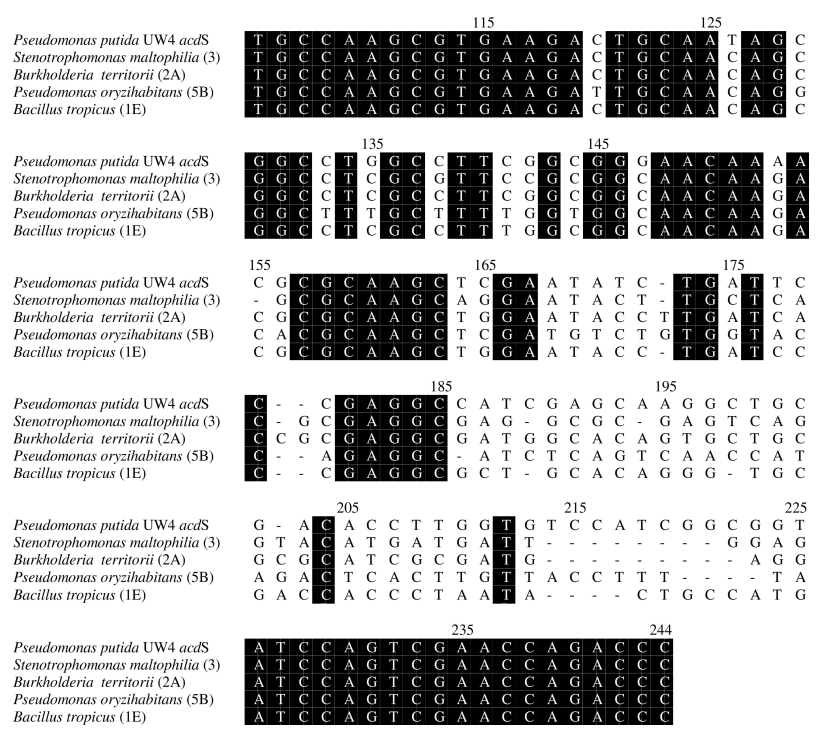

FIGURE 4 Amplified acdS sequence. The displayed sequences are from P. putida UW4 (AY823987) and four isolated strains. The numbers above the nucleotides are the nucleotide position on the acdS sequence of $P$. putida UW4.

abiotic stresses may affect the little diversity of isolated rhizobacteria. The presence of native ACC deaminaseproducing rhizobacteria in the rhizosphere of pineapple plants that have been subjected to herbicide, flooding, and Phytophthora spp. stress indicates that these bacteria may contribute to the stress tolerance of their plant host.

To understand the four bacterial isolates belonging to the ACC-consuming strains, molecular identification and a literature investigation were carried out. A BlastN search revealed that the four isolates belonged to Stenotrophomonas maltophilia (3), Burkholderia territorii (2A), Pseudomonas oryzihabitans (5B), and Bacillus tropicus (1E). Numerous studies, such as those by Mehnaz et al. (2010), Singh and Jha (2017), Weilharter et al. (2011), Kwak et al. (2012), Taghavi et al. (2009), and Misra et al.

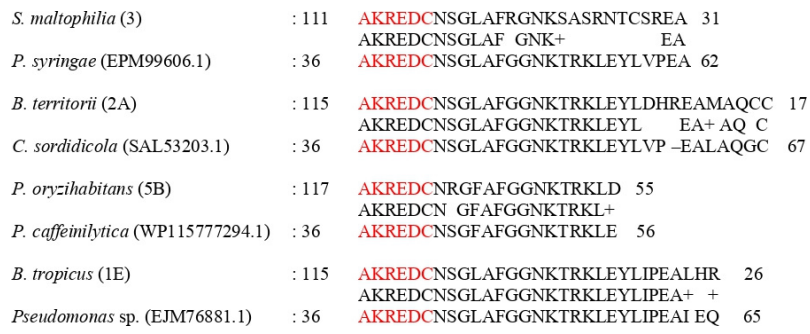

FIGURE 5 Partial amino acid sequence of ACC deaminase. Sequences are from four isolated strains and the closest sequence to amino acid sequences deposited in GenBank. Numbers are the amino acids' positions in the corresponding species. Red letters are the amino acid sequence correspond to the primer 105F-acdS.

(2017), have reported that the genera of these bacteria have ACC deaminase activity under stressful conditions and are very commonly found in the rhizosphere. Although most genera have ACC deaminase activity, not all strains do, or it may be genetically present but not expressed. The presence of the acdS gene encoding this cytoplasmic enzyme in the four genera does not assure that similar genera or strains will appear in a BlastN search. This is due to the amplified partial acdS sequence not representing the complete sequence, and not for identification purposes as a $16 \mathrm{~S}$ rRNA gene. The BlastN search shown in Table 2 displays several strains and there is a pathogenic species, Bacillus anthracis (1E). Singh et al. (2015) stated that ACC deaminase are widely found in human and plant pathogenic species, indicating that this enzyme plays an important role in microbial ecology. Furthermore, the distribution of this type of species in humans does not contribute to pathogenicity for some extent but rather the presence in diverse niche. Notwithstanding the fact that the pathogenic bacteria play role in microbial ecology, the beneficial strains are recommended for agricultural applications and require a preliminary test to determine their adaptation under stressful conditions. 
An efficient and rapid method for the screening of ACC deaminase gene-encoding bacteria is essential because many previous methods are time-consuming. In this study, we developed a set of primers of a structural gene encoding functional protein, ACC deaminase. A good primer design is a crucial factor in supporting successful gene detection. This is important in the field of microbiology, in particular, where a highly conserved gene among different species can be used for wide detection, while a unique sequence for a certain species or strain may provide a very specific test (Hanna et al. 2005). A set of primers were constructed to produce a $140 \mathrm{bp}$ amplicon. This extremely short sequence is recommended for real-time PCR reactions, since it is difficult to generate a secondary structure in order to effectively carry out a PCR run (Toouli et al. 2000). Most importantly, the region of the primer sequence is relatively unique as the presence of amino acid residue at positions $232(\mathrm{~T}), 233(\mathrm{C})$, and $234(\mathrm{G})$, which encode Serine (S78) along with neighbouring residues of the active site of the enzyme are also conserved (Nascimento et al. 2014; Li et al. 2015). The active site of the enzyme is very resistant to collapse and leads to providing the conserved nucleotides encoding the amino acid. $\mathrm{Li}$ et al. (2015) also reported that S78 residue is one of the essential residues for differentiating the acdS gene from its homologs. Despite the fact that degenerative nucleotides are found at the third base $(108,111,114$, and 117), codons at 106 to 120 were relatively conserved in Pseudomonas spp. (Figure 2). This means that there was more than one codon encoding one amino acid, suggesting means that the identical codons encoding an amino acid should be considered in order to pick the appropriate primer sequence.

The primers in this study generally met the criteria described by Dorak (2007), but there were a few inappropriate characters found, such as a GC clamp and primer dimer (Table 3). This can not be denied since the sequence selection is not easy to pick. Therefore, hypothesis of primer dimer formation may occur. However, the success of the

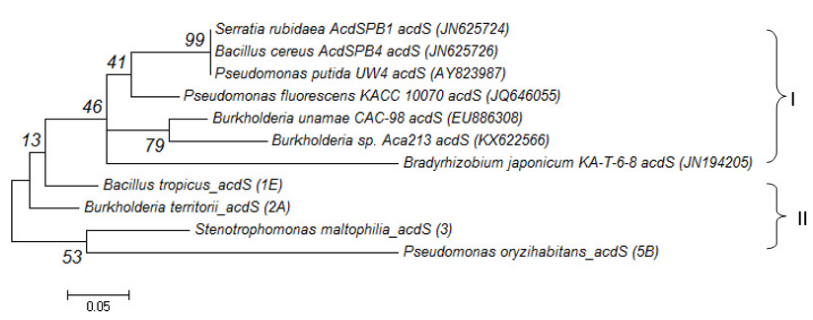

FIGURE 6 Phylogenetic tree of partial acdS sequence of four isolated bacteria (II) and various strains (I) in the NCBI. Group I and II indicate the cluster arbitrarily defined based on topology of the tree. Bootstrap values (1000 replicates) are shown in the nodes. The scale bar represents genetic distance.

primer-template hybridization is also dependent on the reaction optimization and protocol condition. Moreover, a BlastN search is required to validate the specificity of the primer in silico. A BlastN analysis of the primer is recommended to make it $100 \%$ identical to the target gene. This can be observed in the query cover and identity feature. Fortunately, primers 105F-acdS and 244R-acdS bound to the target gene from various genera deposited in the NCBI database, including Pseudomonas, Burkholderia, Serratia, Variovorax, Bacillus, and Ralstonia (data not shown). The specificity of the primers showed that the best melting temperatures relatively covered the ideal temperatures of $60.26-56.51^{\circ} \mathrm{C}$. In addition, no hairpin and no repeats of bases were found.

As a result of the real-time PCR-based method used, melt peak chart analysis revealed that four samples displayed a relatively similar dissociation temperature. An ideal indicator for one amplicon being amplified is that one peak. In fact, this study found two peaks instead (Figure 3). The first peak was in the lower temperature and the other was in the higher temperature. The former is estimated as an intermediate state between dsDNA and ssDNA. As dsDNA begins to dissociate, the stable regions in the sequence (GC-rich) do not dissociate immediately. These stable regions maintain their dsDNA conformation

TABLE 5 BlastX search of amplified acdS sequence in the NCBI database.

\begin{tabular}{|c|c|c|c|c|c|c|}
\hline Isolate & Strain & Feature & Query cover (\%) & E-value & Identity (\%) & Accession number \\
\hline \multirow[t]{3}{*}{3} & Pseudomonas syringae & ACC deaminase & 72 & 0.34 & 63 & EPM99606.1 \\
\hline & Mycobacterium & ACC deaminase & 45 & 0.36 & 88 & WP078309079.1 \\
\hline & Micromonospora sp. & ACC deaminase & 45 & 0.36 & 88 & WP053656558.1 \\
\hline \multirow[t]{3}{*}{$2 \mathrm{~A}$} & Caballeronia sordidicola & ACC deaminase & 85 & $4 e-09$ & 85 & SAL53203.1 \\
\hline & Paraburkholderia diazotrophica & ACC deaminase & 85 & $1 e-08$ & 82 & SEK09076.1 \\
\hline & Verticillium dahlia & ACC deaminase & 85 & $2 e-08$ & 82 & XP009658014.1 \\
\hline \multirow[t]{3}{*}{$5 B$} & Paraburkholderia caffeinilytica & ACC deaminase & 53 & $2 e-04$ & 90 & WP115777294.1 \\
\hline & Burkholderia sp. & ACC deaminase & 53 & $2 e-04$ & 90 & KPD18714.1 \\
\hline & Pseudomonas syringae & ACC deaminase & 53 & $4 e-04$ & 86 & EPM82313.1 \\
\hline \multirow[t]{3}{*}{$1 \mathrm{E}$} & Pseudomonas sp. & ACC deaminase & 77 & $1 e-10$ & 90 & EJM76881.1 \\
\hline & Paraburkholderia caribensis & ACC deaminase & 72 & $2 e-10$ & 100 & ACH81537.1 \\
\hline & Pseudomonas brassicacearum & ACC deaminase & 77 & $3 e-10$ & 93 & AEO62172.1 \\
\hline
\end{tabular}

3 = Stenotrophomonas maltophilia; 2A = Burkholderia territorii; 5B = Pseudomonas oryzihabitans; $1 \mathrm{E}=$ Bacillus tropicus. 
until the temperature is sufficiently high to cause it to dissociate. This leads to the formation of a specific peak at the higher temperature. Obviously, this is one amplicon (Dwight et al. 2011). Meanwhile, the formation of the primer dimer in the NTC reaction is due to the presence of the complementary sequence at the 3 ' end of the two primers during the PCR reaction. Thus, a shorter sequence will be formed. This allows the primer dimer to have a lower dissociation temperature than the target gene (Poritz and Ririe 2014). The dissociation temperatures of the amplified sequence of the four samples were relatively similar, but their dissimilarities indicated that there were four acdS sequences with different GC contents and distribution and/or a different GC/AT ratio.

The results of BlastN and BlastX searches showed that the amplified sequence was an acdS sequence encoding ACC deaminase of around 140 bp were aligned in the GenBank database and showed acdS gene feature with identities in the range of $89-96 \%$. Furthermore, the sequences were distributed in various bacteria. This result corresponds to that of Singh et al. (2015), who reported that the presence of ACC deaminase gene-encoding bacteria was widespread among Proteobacteria. The identical percentages of the acdS sequence to that of $P$. putida UW4 in samples 3, 2A, 5B, and $1 \mathrm{E}$ were $70.71 \%$, 78.57\%, 67.14\%, and $78.57 \%$ respectively, while the GC contents were $55.71 \%$, $60 \%$, 48.57\%, and 58.57\%, respectively. The higher GC content in the samples of Burkholderia territorii (2A) and Bacillus tropicus (1E) contributed to the higher dissociation temperature compared with Stenotrophomonas maltophilia (3) and Pseudomonas oryzihabitans (5B), as reflected in the melt peak chart (Figure 3). On the other hand, the identical sequence contributed to the construction of the phylogenetic tree.

Phylogenetic analysis of the partial acdS sequence from various bacterial strains was carried out to investigate the evolution of this gene. The acdS sequences of Burkholderia territorii and Bacillus tropicus were closer related than the two other sequences. This indicated that the acdS sequence of both strains evolved from that of Stenotrophomonas maltophilia and Pseudomonas oryzihabitans. The resemblance of the four amplified acdS sequences was separated into a different group compared with those of many bacteria deposited in the GenBank sequence database. We may therefore conclude that the four acdS sequences from the rhizosphere of the pineapple plants take place in group II as an ancestral group. Polymorphism of the acdS sequence at the same genera shows that the different clade of the same genera may be affected by different geographical origins and/or plant hosts, and leads to group separation in the phylogenetic tree.

\section{Conclusions}

Approximately $14.28 \%$ of ACC deaminase-producing rhizobacteria were successfully grown on selective medium. Four isolates with the best growth performance were identified as Stenotrophomonas maltophilia (3), Burkholderia territorii (2A), Pseudomonas oryzihabitans (5B), and Bacillus tropicus (1E), and they belonged to ACCconsuming strains. The four bacterial strains possess an ACC deaminase gene (acdS), as confirmed by sequencing analysis and Blast searches. These four partial acdS sequences are separated into an ancestral group compared with those of many other strains deposited in the GenBank database, which may be affected by their geographical origins, environmental conditions, and plant hosts. Therefore, ACC deaminase-producing rhizobacteria obtained from the rhizosphere of stressed pineapple plants may contribute to the plant host's tolerance to stress.

\section{Acknowledgments}

This research was funded by LPDP (Indonesian Endowment Fund for Education) from the Ministry of Finance, Education, Research and Technology, and Religion of Indonesia and partly supported by DIPA LIPI (Indonesian Institute of Sciences). We would also like to thank Hanim (Bogor Agricultural University, Bogor, Indonesia) as our co-worker for helping this research run well, as well as LIPI for providing the research facilities and laboratory.

\section{Authors' contributions}

$\mathrm{G}$ and NN were the supervisors of this research. They fully contributed to the guidance of this research and improvement of the final manuscript of this article. G was authorized for the very final version of the manuscript. SA contributed to developing the research topic, improving the manuscript, and providing laboratory facilities.

\section{Competing interests}

The authors declare no competing interests.

\section{References}

Bal HM, Das S, Dangar TK, Adhya TK. 2013. ACC deaminase and IAA producing growth promoting bacteria from the rhizosphere soil of tropical rice plants. J Basic Microbiol. 53(12):972-984. doi:10.1002/jobm. 201200445.

Bray EA, Bailey-Serres J, Weretilnyk E. 2000. Responses to abiotic stresses. In: Buchanan BB, Gruissem W, Jones RL, editors. Biochemistry and molecular biology of plants. Rockville: American Society of Plant Physiologists. p. 1158-1203.

Dorak MT. 2007. Real-time PCR. London: Taylor \& Francis. doi:10.4324/9780203967317.

Duan J, Müller KM, Charles TC, Vesely S, Glick BR. 2009. 1-Aminocyclopropane-1-carboxylate (ACC) deaminase genes in rhizobia from southern Saskatchewan. Microb Ecol. 57(3):423-436. doi: 10.1007/s00248-008-9407-6.

Dwight Z, Palais R, Wittwer CT. 2011. uMELT: prediction of high-resolution melting curves and dynamic melting profiles of PCR products in a rich web application. Bioinformatics. 27(7):1019-1020. doi:10.1093/ bioinformatics/btr065. 
Glick BR. 2014. Bacteria with ACC deaminase can promote plant growth and help to feed the world. Microbiol Res. 169(1):30-39. doi:10.1016/j.micres.2013. 09.009.

Glick BR, Cheng Z, Czarny J, Duan J. 2007. Promotion of plant growth by ACC deaminase-producing soil bacteria. In: Bakker PAHM, Raaijmakers JM, Bloemberg G, Höfte M, Lemanceau P, Cooke BM, editors. New perspectives and approaches in plant growth-promoting rhizobacteria research. Dordrecht: Springer. p. 329-339. doi:10.1007/ s10658-007-9162-4.

Glick BR, Penrose DM, Li J. 1998. A model for the lowering of plant ethylene concentrations by plant growthpromoting bacteria. J Theor Biol. 190(1):63-68. doi: 10.1006/jtbi.1997.0532.

Hanna SE, Connor CJ, Wang HH. 2005. Real-time polymerase chain reaction for the food microbiologist: technologies, applications, and limitations. J Food Sci. 70(3):49-53. doi:10.1111/j.1365-2621.2005.tb07149. $\mathrm{x}$.

Honma M, Shimomura T. $1978 . \quad$ Metabolism of 1-aminocyclopropane-1-carboxylate deaminase. Agric Biol Chem. 42(10):1825-1831. doi:10.1080/00021369.1978.10863261.

Kaur G, Kumar S, Nayyar H, Upadhyaya HD. 2008. Cold stress injury during the pod-filling phase in chickpea (Cicer arietinum L.): effects on quantitative and qualitative components of seeds. J Agron Crop Sci. 194(6):457-464. doi:10.1111/j.1439-037X.2008. 00336.x.

Kende H. 1993. Ethylene biosynthesis. Annu Rev Plant Physiol Plant Mol Biol. 44(1):283-307. doi:10.1146/ annurev.pp.44.060193.001435.

Kwak MJ, Song JY, Kim SY, Jeong H, Kang SG, Kim BK, Kwon SK, Lee CH, Yu DS, Park SH, Kim JF. 2012. Complete genome sequence of the endophytic bacterium Burkholderia sp. strain KJ006. J Bacteriol. 24(16):4432-4433. doi:10.1128/JB.00821-12.

Lane DJ. 1991. 16S/23S rRNA sequencing. In: Stackebrandt E, Goodfellow M, editors. Nucleic acid techniques in bacterial systematics. New York: John Wiley and Sons. p. 115-175.

Li Z, Chang S, Ye S, Chen M, Lin L, Li Y, Li S, An Q. 2015. Differentiation of 1-aminocyclopropane-1carboxylate (ACC) deaminase from its homologs is the key for identifying bacteria producing ACC deaminase. FEMS Microbiol Ecol. 91(10):fiv112. doi: 10.1093/femsec/fiv112.

Ma W, Guinel FC, Glick BR. 2003. Rhizobium leguminosorum biovarviciae 1-aminocyclopropane-1carboxylate deaminase promotes nodulation of pea plants. Appl Environ Microbiol. 69(8):4396-4402. doi:10.1128/aem.69.8.4396-4402.2003.

Mehnaz S, Baig DN, Lazarovits G. 2010. Genetic and phenotypic diversity of plant growth promoting rhizobacteria isolated from sugarcane plants growing in Pakistan. J Microbiol Biotechnol. 20(12):1614-1623.
Misra S, Dixit VK, Khan MH, Mishra SK, Dviwedi G, Yadav S, Lehri A, Chauhan PS. 2017. Exploitation of agro-climate environment for selection of 1aminocyclopropane-1-carboxylic acid (ACC) deaminase producing salt tolerant indigenous plant growth promoting rhizobacteria. Microbiol Res. 205:25-34. doi:10.1016/j.micres.2017.08.007.

Nascimento FX, Rossi MJ, Soares CRFS, McConkey BJ, Glick BR. 2014. New insights into 1aminocyclopropane-1-carboxylate (ACC) deaminase phylogeny, evolution and ecological significance. PLoS ONE. 9(6):e99168. doi:10.1371/journal.pone. 0099168.

Penrose DM, Glick BR. 2003. Methods for isolating and characterizing ACC deaminase-producing plant growth-promoting rhizobacteria. Physiol Plant. 118(1):10-15. doi:10.1034/j.1399-3054.2003.00086. $\mathrm{X}$.

Poritz MA, Ririe KM. 2014. Getting things backwards to prevent primer dimers. J Mol Diagn. 16(2):159-162. doi:10.1016/j.jmoldx.2014.01.001.

Singh RP, Ganesh MS, Anil K, Prabhat NJ. 2015. Biochemistry and genetics of ACC deaminase: a weapon to "stress ethylene" produced in plants. Front Microbiol. 6:937. doi:10.3389/fmicb.2015.00937.

Singh RP, Jha PN. 2017. The PGPR Stenotrophomonas maltophilia SBP-9 augments resistance against biotic and abiotic stress in wheat plants. Front Microbiol. 8:1945. doi:10.3389/fmicb.2017.01945.

Taghavi S, Garafola C, Monchy S, Newman L, Hoffman A, Weyens N, Barac T, Vangronsveld J, van der Lelie D. 2009. Genome survey and characterization of endophytic bacteria exhibiting a beneficial effect on growth and development of poplar trees. Appl Environ Microbiol. 75(3):748-757. doi:10.1128/AEM.02239-08.

Thakur P, Kumar S, Malik JA, Berger JD, Nayyar H. 2010. Cold stress effects on reproductive development in grain crops: an overview. J Exp Bot. 67(3):429-443. doi:10.1016/j.envexpbot.2009.09.004.

Timmusk S, Paalme V, Pavlicek T, Bergquist J, Vangala A, Danilas T, Nevo E. 2011. Bacterial distribution in the rhizosphere of wild barley under contrasting microclimates. PLoS ONE. 6(3):e17968. doi:10.1371/ journal.pone.0017968.

Toouli CD, Turner DR, Grist SA. 2000. The effect of cycle number and target size on polymerase chain reaction amplification of polymorphic repetitive sequences. Anal Biochem. 280(2):324-326. doi:10. 1006/abio.2000.4547.

Varma A, Lynette A, Dietrich W, Rudiger H. 2004. Plant surface microbiology. Heidelberg: Springer-Verlag. doi:10.1007/978-3-540-74051-3.

Weilharter A, Mitter B, Shin MV, Chain PS, Nowak J, Sessitsch A. 2011. Complete genome sequence of the plant growth-promoting endophyte Burkholderia phytofirmans strain PsJN. J Bacteriol. 193(13):33833384. doi:10.1128/JB.05055-11. 